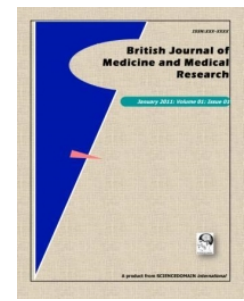

British Journal of Medicine \& Medical Research 3(1): 189-197, 2013

SCIENCEDOMAIN international

www.sciencedomain.org

\title{
Primary Pyomyositis Mimicking Soft-tissue Sarcoma: A Case Report
}

\author{
Amreeta Dhanoa $^{1^{*}}$, Vivek Ajit Singh $^{2}$ and Anushya Vijayananthan ${ }^{3}$ \\ ${ }^{1}$ Jeffrey Cheah School of Medicine and Health Sciences, Monash University Sunway \\ Campus, 46150 Sunway, Malaysia. \\ ${ }^{2}$ Department of Orthopaedic Surgery, University of Malaya, 50603 Kuala Lumpur, Malaysia. \\ ${ }^{3}$ Department of Biomedical Imaging, University of Malaya, 50603 Kuala Lumpur, Malaysia.
}

\section{Authors' contributions}

This work was carried out in collaboration between all authors. Author AD wrote and edited the manuscript. Author VAS was the Orthopaedic Oncologist who treated and planned the management of the patient and was involved in critical appraisal of the manuscript. Author

$A V$ was the Radiologist who reviewed the radiology images and was involved in critical appraisal of the manuscript. All authors read and approved the final manuscript.

\section{Case Report}

Received $19^{\text {th }}$ July 2012

Accepted $23^{\text {rd }}$ November 2012 Published $9^{\text {th }}$ January 2013

\section{ABSTRACT}

Aims: Our aim was to present a case of pyomyositis and highlight the need to distinguish it from a soft-tissue sarcoma which it can closely mimic.

Presentation of Case: We report a 51-year old diabetic patient who presented with a painful swelling in the right upper arm, which was not associated with fever. The mass was well defined, tender and firm but lacked other signs of inflammation such as redness or increased local warmth. Even the magnetic resonance imaging (MRI) findings were more in favor of a soft-tissue sarcoma. A diagnosis of pyomyositis was revealed when the trucut biopsy performed, yielded frank pus discharge.

Discussion and Conclusion: This case illustrates a diagnostic quandary of a soft tissue mass. There may be a paucity of inflammatory signs in patients with an underlying immunocompromised state, masking an initial diagnosis of pyomyositis. Although softtissue sarcomas generally present as painless lumps, they can be painful especially with larger tumors that are increasing in size, further adding to a diagnostic dilemma. While MRI is a valuable tool for early diagnosis of pyomyositis, it can still be misleading. Prompt biopsy is recommended to facilitate the correct diagnosis. 
Keywords: Pyomyositis; muscle; soft-tissue sarcoma; mimic; misdiagnose; MRI.

\section{INTRODUCTION}

Primary pyomyositis is a subacute, deep bacterial infection of skeletal muscle, with no obvious local or adjacent source of infection [1]. Pyomyositis is an unusual entity as skeletal muscle is relatively resistant to bacterial infection. Smith and Vickers [2] reported only 2 muscle abscesses amongst 327 patients who died of staphylococcal septicemia, suggesting that bacteremia alone is not sufficient to cause an intramuscular abscess. It has been suggested that concomitant muscular insult by an unrecognized trauma may allow implantation of bacteria from an unrelated bacteremic episode [3]. Pyomyositis has a wide array of clinical manifestations and has been misdiagnosed as muscle strain, thrombophlebitis, cellulitis, bursitis, haematoma, arthritis, osteomyelitis and even soft-tissue sarcoma [1]. As a consequence of the rarity of this condition and its' nebulous clinical presentation, the diagnosis of pyomyositis is often delayed compromising patient management. Herein, we report a patient with pyomyositis, initially misdiagnosed as softtissue sarcoma based on clinical and radiological findings. A review of cases with similar initial misled impression is also discussed.

\section{PRESENTATION OF CASE}

A 51-year old female patient was referred from a private hospital to our orthopaedic oncology clinic for a large mass in the right arm. She first noted the mass 3 months ago which has been increasing in size over the past 4 weeks. This was associated with throbbing pain which sometimes disturbed her sleep at night. However, she did not have any weakness or numbness of the upper limb. She denied any fever, chills and there was no prior history of trauma or bleeding disorder. She reported no illicit drug use, recent traveling or contact with any patients with tuberculosis. There was no significant history of loss of appetite or weight. She is an insulin-dependent diabetic on regular follow up and treatment. She also had a left thyroidectomy done for a multinodular goitre 4 years back.

Physical examination revealed a mass over the anterior aspect of her right upper arm, which was well defined, tender, immobile and firm with no signs of inflammation such as redness or increased local warmth of the overlying skin. It measured approximately $10 \times 10 \mathrm{~cm}$ in diameter. The surrounding skin was shiny and superficial veins were dilated. There were no palpable axillary or supraclavicular lymph node enlargement. There was also no associated muscle weakness or sensory loss of the upper limb.

On admission, the patient was afebrile (temperature $36.9^{\circ} \mathrm{C}$ ) and her vital signs were stable (blood pressure 135/80 and pulse rate 70 beats/minute). Her blood investigation showed a leukocyte count of $10,500 / \mathrm{mm}^{3}$ with an unremarkable differential. The erythrocyte sedimentation rate (ESR) and C-reactive protein were both raised at $78 \mathrm{~mm} / \mathrm{hour}$ and 50 $\mathrm{mg} / \mathrm{dL}$ respectively. Her blood glucose level on admission was $8.2 \mathrm{mmol} / \mathrm{L}$.

Plain radiograph showed a dense soft tissue mass around the right shoulder (Fig. 1). 


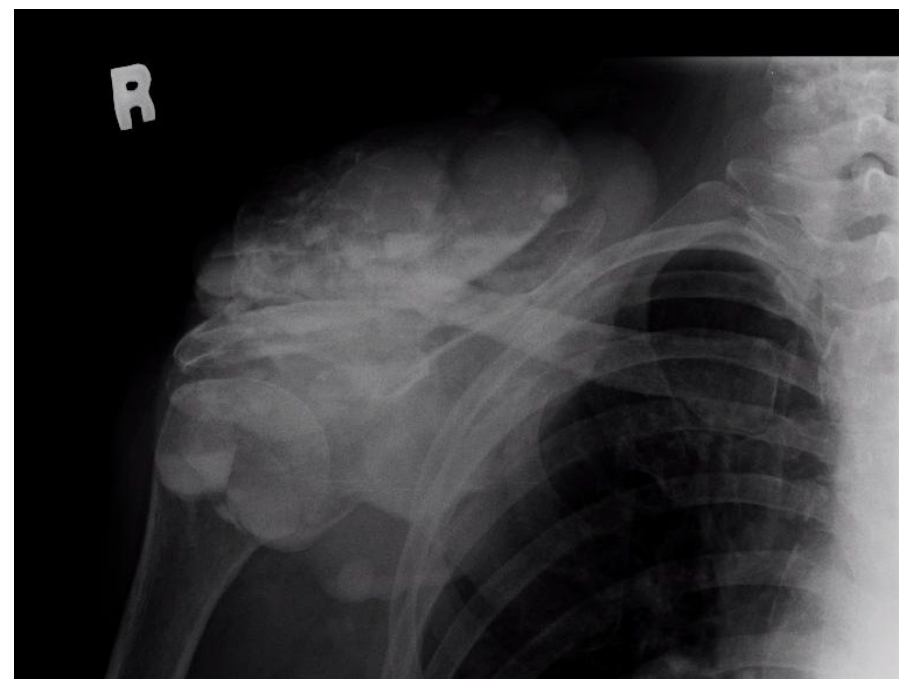

Fig. 1. Plain radiograph of right shoulder showed a lobulated mass over the right shoulder region

Fig. 2a is the coronal T1WI image which shows a lobulated mass of low signal intensity (signal intensity similar to surrounding muscle) with no underlying bone infiltration. Fig. $2 \mathrm{~b}$ is the T1 axial image which shows similar findings as above. It does not show the low signal intensity of fluid to suggest an abscess.
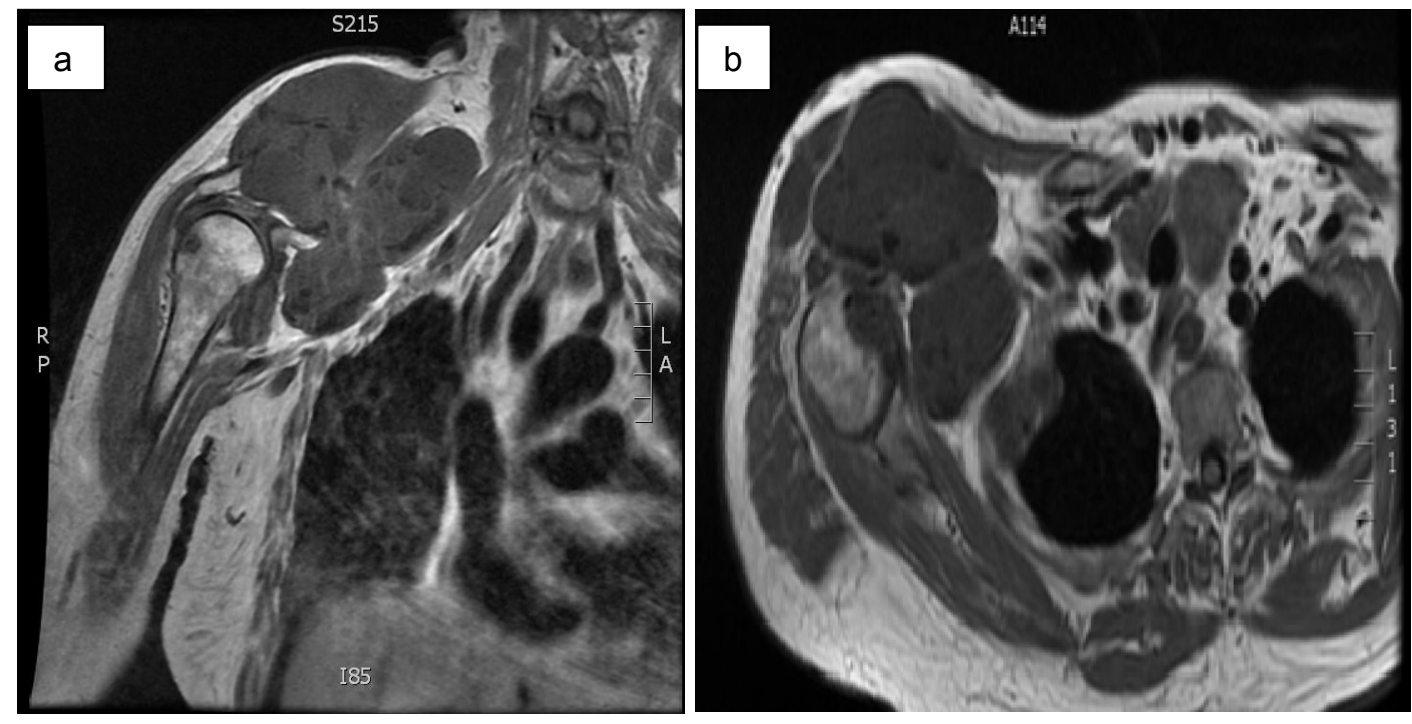

Fig. 2. Magnetic resonance imaging scans. (a) coronal section and (b) axial section of mass

Fig. 3 is the coronal T1 fat saturated post gadolinium image which shows areas of enhancement within the low signal intensity mass. This suggests that this is likely to be a necrotic tumour. 


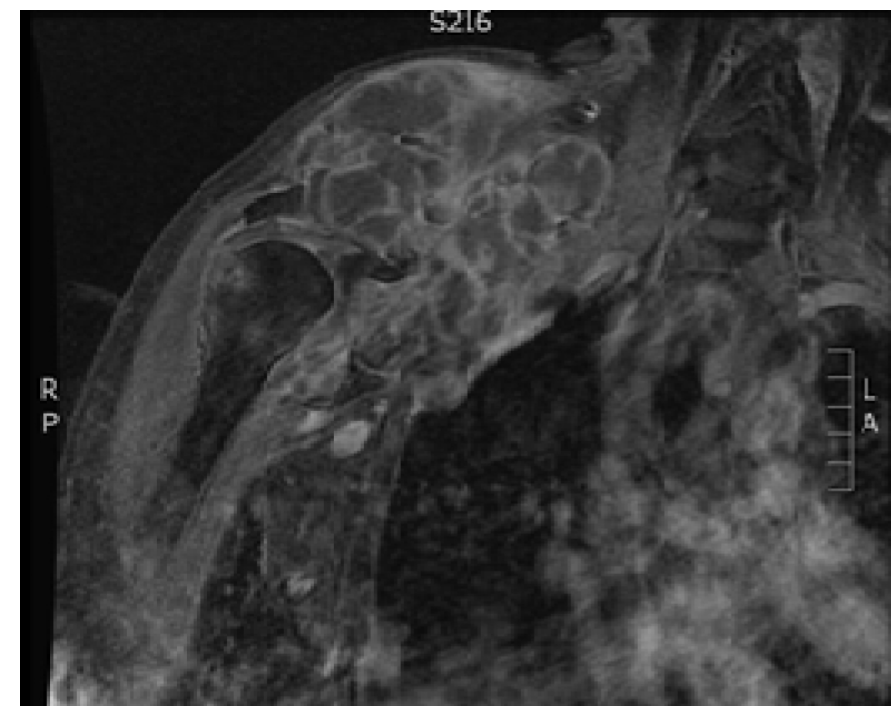

Fig. 3. Postgadolinium image of right shoulder

Based on the clinical and radiological findings, a soft-tissue sarcoma was suspected and a trucut needle biopsy was carried out on the same day which unexpectedly revealed purulent discharge. We immediately proceeded to an incision and drainage (Fig. 4).
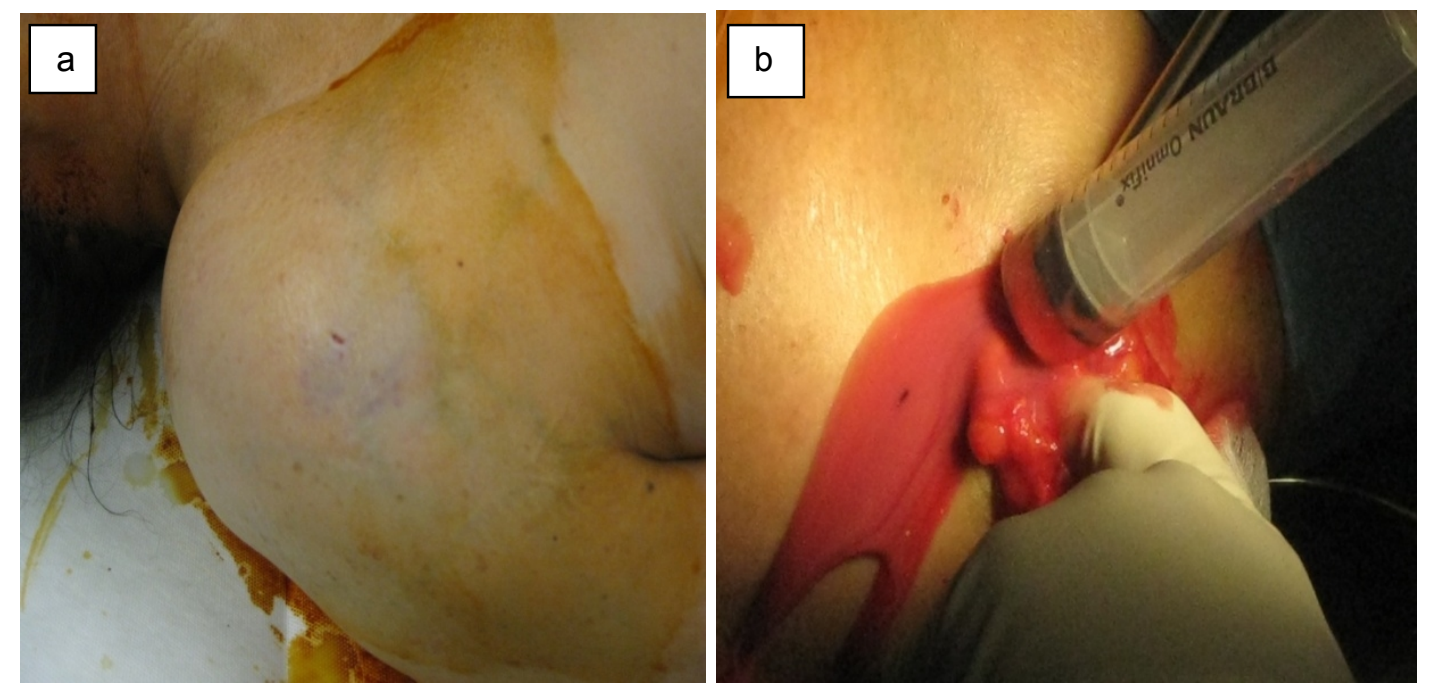

Fig. 4 (a). Swelling with superficial dilated veins seen over the right shoulder (b) pus aspirated from the right shoulder

Gram stain examination of the pus showed clusters of gram positive cocci and numerous neutrophils. Thereafter, the patient was started on intravenous cloxacillin; 1000mg every 6 hourly. Culture of the pus later revealed methicillin-susceptible Staphylococcus aureus. Blood culture did not grow any organisms. Her condition improved dramatically after drainage and commencement of intravenous cloxacillin. She was discharged after completing 2 weeks of intravenous cloxacillin, with oral cloxacillin 1 gram every 6 hourly for 
another 8 weeks. At 2 weeks post-discharge follow-up, the leukocyte counts, ESR and CRP were $7.1 \times 10^{9} / \mathrm{L}, 28 \mathrm{~mm} / \mathrm{hour}$ and $0.4 \mathrm{mg} / \mathrm{dL}$ respectively. At one-month follow-up, the wound had healed completely and the inflammatory markers had normalized. At two years follow up, there were no recurrent episodes of infection and the patient remained asymptomatic.

\section{DISCUSSION}

This case illustrates the enigma of diagnosing a soft tissue mass, despite the advent of modern imaging modalities. All too frequently, benign soft-tissue lesions like aneurysms, haematomas and benign masses have been erroneously diagnosed as soft-tissue sarcoma $[4,5]$. Another important differential for soft tissue swelling sometimes confused with softtissue sarcoma is pyomyositis $[6,7,8,9]$. However, it is necessary to maintain a high index of suspicion when a patient presents with a large, increasing in size, deep seated soft-tissue mass as it may be a soft-tissue sarcoma, which if overlooked may have catastrophic outcome.

Literature search revealed six other cases of pyomyositis mimicking soft-tissue sarcomas and the features are summarized in Table 1.

All patients presented with a soft-tissue mass. Apart from patient number 1 and 4 who complained of symptoms of more than 3 months, the duration of symptoms in all the other patients was 2 months or less. With the exception of patient 1 and 4 who seem to have a more chronic involvement, the clinical presentations consistently present in all patients were pain and tenderness of swelling. Whilst pyomyositis normally presents as localized muscle pain and tender swelling, soft-tissue sarcomas are generally painless, slow-growing mass. However, sarcomas can present with pain especially in large tumours due to pressure and stretching of the surrounding structures [10]. In fact, any soft tissue lump exhibiting any of these four clinical features should be considered to be malignant until proved otherwise: (i) increasing in size; (ii) size $>5 \mathrm{~cm}$; (iii) painful; or (iv) deep to the deep fascia [11]. Our patient actually manifested with the first 3 presentations.

The diagnosis may be further deluded if the affected muscle is deeply situated as obvious inflammatory signs such as erythema and warmth may not be apparent, further favoring a diagnosis of sarcoma. Systemic symptoms such as fever, reduced appetite and weight loss may not be reliable indicators for diagnosis as they may or may not be present in both these conditions $[6,8,10]$. The presence of diabetes mellitus or other immunosuppressive conditions may further camouflage an infectious process, e.g. the absence of leukocytosis and fever as was the case in our patient. Pyomyositis is increasingly described among immunocompromised people such as those with human immunodeficiency virus infection, malignancies, connective tissue disorders or diabetes mellitus and amongst intravenous drug users [1,12]. Bickels [1] in his review also noted that approximately half of all patients aged more than 30 years with pyomyositis had a concomitant condition associated with impaired immune status. 
Table 1. Review of pyomyositis cases mimicking soft-tissue sarcomas

\begin{tabular}{|c|c|c|c|c|c|c|c|c|c|c|c|c|c|c|c|}
\hline \multirow[b]{2}{*}{ 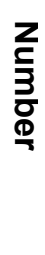 } & \multirow[b]{2}{*}{ 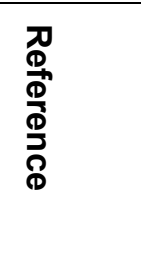 } & \multirow[b]{2}{*}{ 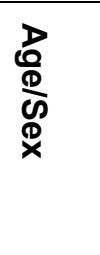 } & \multicolumn{6}{|c|}{ Signs and symptoms } & \multirow[b]{2}{*}{ 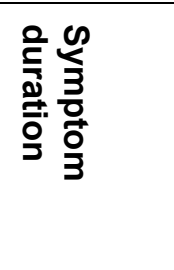 } & \multirow[b]{2}{*}{ 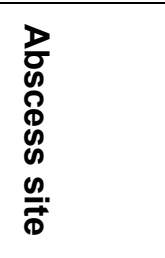 } & \multirow{2}{*}{ 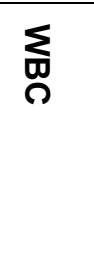 } & \multirow[b]{2}{*}{ 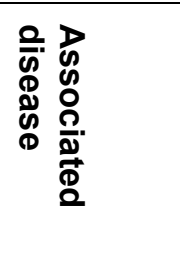 } & \multirow[b]{2}{*}{$\frac{D}{\omega}$} & \multirow[b]{2}{*}{ 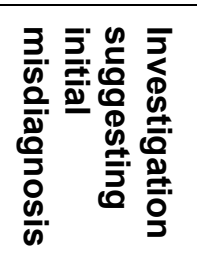 } & \multirow[b]{2}{*}{$\begin{array}{l}-1 \\
\bar{D} \\
\stackrel{D}{1} \\
\stackrel{5}{3} \\
\frac{1}{2} \\
2\end{array}$} \\
\hline & & & 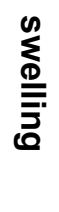 & D. & $\underset{\Phi}{\stackrel{\mathbb{D}}{\Phi}}$ & 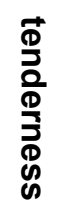 & $\frac{\S}{3}$ & 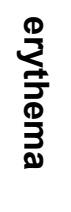 & & & & & & & \\
\hline 1 & 6 & $39 / \mathrm{M}$ & $\mathrm{Y}$ & $\mathrm{N}$ & $\mathrm{Y}$ & $\mathrm{N}$ & $\mathrm{Y}$ & $\mathrm{Y}$ & 3 months & Thigh & 12 & None & S. aureus & CT & $\begin{array}{l}\text { Excision \& } \\
\text { Antibiotics }\end{array}$ \\
\hline 3 & 8 & $46 / \mathrm{M}$ & Y & $\mathrm{Y}$ & $\mathrm{Y}$ & Y & $\mathrm{Y}$ & $\mathrm{N}$ & 4 weeks & Thigh & 18.5 & None & S. aureus & $\begin{array}{l}\text { CT scan, } \\
\text { Profunda } \\
\text { femoris } \\
\text { arteriogram }\end{array}$ & $\begin{array}{l}\text { I \& D } \\
\text { Antibiotics }\end{array}$ \\
\hline 4 & 8 & 19/F & $\mathrm{Y}$ & $\mathrm{N}$ & $\mathrm{N}$ & $\mathrm{N}$ & $\mathrm{N}$ & NA & 1 year & Forearm & 8.9 & None & no & $\begin{array}{l}\text { Roentgen- } \\
\text { ogram }\end{array}$ & $\begin{array}{l}\text { En bloc } \\
\text { excision }\end{array}$ \\
\hline 5 & 8 & 15/F & $\mathrm{Y}$ & $\mathrm{Y}$ & $\mathrm{N}$ & $\mathrm{Y}$ & NA & $\mathrm{N}$ & 2 months & $\begin{array}{l}\text { Para- } \\
\text { lumbar }\end{array}$ & 7.8 & None & no & Clinical & $\begin{array}{l}\text { En bloc } \\
\text { excision }\end{array}$ \\
\hline 6 & 9 & $77 / \mathrm{M}$ & $\mathrm{Y}$ & $\mathrm{Y}$ & $\mathrm{Y}$ & $\mathrm{Y}$ & NA & NA & 2 months & Thigh & 11.5 & $\begin{array}{l}\text { History of } \\
\text { renal } \\
\text { adenocar- } \\
\text { cinoma \& } \\
\text { left hip } \\
\text { prosthesis }\end{array}$ & $\begin{array}{l}\text { Yersinia } \\
\text { enteroco- } \\
\text { litica }\end{array}$ & MRI & $\begin{array}{l}\text { Excision \& } \\
\text { Antibiotics }\end{array}$ \\
\hline 7 & Current & $51 / F$ & $\mathrm{Y}$ & $\mathrm{Y}$ & $\mathrm{N}$ & $\mathrm{Y}$ & $\mathrm{N}$ & $\mathrm{N}$ & 4 weeks & Shoulder & 10.5 & $\begin{array}{l}\text { Diabetes } \\
\text { mellitus }\end{array}$ & S. aureus & MRI & $\begin{array}{l}\text { I \& D } \\
\text { Antibiotics }\end{array}$ \\
\hline
\end{tabular}


Of the 7 patients presenting as mimics of soft-tissue sarcoma (Table 1), 4 patients had involvement of the thigh muscles. The other 3 patients had involvement of the paralumbar, forearm and shoulder girdle muscles (our patient) respectively. The occurrence of pyomyositis at the shoulder girdle is relatively less common and in a recent compilation of 676 cases of primary pyomyositis [1]; the most common muscles involved were the quadriceps $(26.3 \%)$, followed by iliopsoas $(14 \%)$ and gluteal muscles $(10 \%)$. Only $7.9 \%$ of all cases involved the shoulder girdle muscles.

Routine laboratory tests are generally nonspecific and may not suggest an infectious process, further adding on to the diagnostic quandary. Leukocytosis was noted in only 3 out of 7 patients with pyomyositis (Table 1). Blood cultures may be negative, as it was in this case. Indeed, only $31 \%$ of cases of pyomyositis in North America documented positive blood cultures [13]. An infectious process was not expected in our patient given that the patient had been symptomatic for 4 weeks, was afebrile and did not have leukocytosis. Crum [12] showed that whilst leukocytosis was common among healthy patients, patients with immunocompromised conditions are frequently associated with low or normal leukocyte counts.

Due to a high suspicion of soft-tissue sarcoma based on clinical and radiological findings, a trucut biopsy was performed which unexpectedly yielded pus. Cultures of abscess usually reveal organisms in $21 \%$ to $41 \%$ of patients [1]. A preliminary gram stain result is highly valuable in determining the initial antibiotic of choice, as the complete culture results may take another 2 to 3 days. In our patient, the presence of gram positive cocci in clusters favored staphylococcus and appropriately cloxacillin was commenced. The predominantly cultured organism in reported series was Staphylococcus aureus, ranging from $64 \%$ to $90 \%$ $[3,12]$. Other bacterial causes of pyomyositis included Streptococcus pyogenes, Escherichia coli, Salmonella species and Mycobacterium species [3,12].

Plain radiography is helpful to exclude primary bone lesions, such as subacute osteomyelitis or primary bone sarcoma. However, it may not facilitate a diagnosis of pyomyositis as the suggestive appearance such as muscle inflammation and abscess formation may not be evident. These appearances are evident in a MRI, which is the most useful imaging modality for the diagnosis of pyomyositis [1]. In the early phases, the MRI findings include muscle enlargement with heterogeneous T2 signal hyperintensity and minimal hyperintensity on T1weighted sequences, whilst at the liquefactive stages a T2 hyperintensity with a corresponding decrease in T1 signal intensity may be noted [14]. However, the MRI appearance in our patient did not show the classical features of pyomyositis and highly favored a soft tissue sarcoma; misleading our initial diagnosis. MRI with gadolinium enhancement increases the likelihood of recognizing abscesses allowing the selection of patients for percutaneous drainage or surgical debridement [15].

Nielsen [16] has described three phases in the clinical development of pyomyositis: an invasive phase, a suppurative phase and a septic phase, in which abscess spreads. Our patient, who had been symptomatic for 4 weeks and had massive purulent involvement of the shoulder musculature, was in the suppurative phase. Timely diagnosis and appropriate treatment of pyomyositis is essential in averting considerable adjacent tissue destruction, compartment syndrome and even life-threatening sepsis [1]. Whilst patients at the early stages of pyomyositis may be managed with antimicrobial therapy alone those at the advanced stages are best managed by a combination of surgical drainage and antimicrobial therapy. 


\section{CONCLUSION}

The following case emphasized the diagnostic dilemma of a soft tissue mass despite the availability of sophisticated modern imaging techniques. Although there have been relatively few reports of pyomyositis mimicking soft-tissue sarcoma in the literature, it should be considered as a mimicker of soft-tissue sarcoma. Although soft-tissue sarcomas are generally painless, they can be painful especially with larger tumours that are increasing in size, further adding to a diagnostic quandary. While MRI is a valuable tool for early diagnosis of pyomyositis, having a high sensitivity to reactive inflammatory changes, it can still be misleading. Prompt biopsy is recommended to facilitate the correct diagnosis and treatment, to avoid extensive muscle damage.

\section{CONSENT}

All authors declare that written informed consent was obtained from the patient for publication of this case report and accompanying images.

\section{COMPETING INTERESTS}

Authors have declared that no competing interests exist.

\section{REFERENCES}

1. Bickels J, Ben-Sira L, Kessler A, Wientroub S. Primary pyomyositis. J Bone Joint Surg Am. 2002;84-A(12):2277-86.

2. Smith IM, Vickers AB. Natural history of 338 treated and untreated patients with staphylococcal septicaemia (1936-1955). Lancet. 1960;1(7138):1318-22.

3. Chiedozi LC. Pyomyositis. Review of 205 cases in 112 patients. Am J Surg. 1979;137(2):255-9.

4. Rajapakse BN, Kiddle G. Calcifying haematoma mimicking a soft tissue sarcoma and myositis ossificans. ANZ J Surg. 2006;76(11):1027-9.

5. Boyer MI, Wang EH, Bell RS. Ruptured deep femoral artery aneurysm simulating a soft-tissue sarcoma: a case report. Can J Surg. 1995;38(1):92-4.

6. Pittam MR. Pyomyositis mimicking soft-tissue sarcoma. Eur $\mathrm{J}$ Surg Oncol. 1988;14(5):459-61.

7. Reid SE, Nambisan R, Karakousis CP. Pyomyositis: a differential diagnosis from sarcoma. J Surg Oncol. 1985;29(3):143-6.

8. Tucker RE, Winter WG, Del Valle C, Uematsu A, Libke R. Pyomyositis mimicking malignant tumor. Three case reports. J Bone Joint Surg Am. 1978;60(5):701-3.

9. Gautier E, Carniel E, Génin J, Tancrède C. Tumor-like pyomyositis of the thigh caused by Yersinia enterocolitica. Clin Infect Dis. 1996;23(3):658-9.

10. Damron TA, Beauchamp CP, Rougraff BT, Ward WG. Soft-tissue lumps and bumps. J Bone Joint Surg. 2003;85:1142-55.

11. Johnson CJ, Pynsent PB, Grimer RJ. Clinical features of soft tissue sarcomas. Ann R Coll Surg Engl. 2001;83(3):203-5.

12. Crum NF. Bacterial pyomyositis in the United States. Am J Med. 2004;117(6):420-8.

13. Christin L, Sarosi GA. Pyomyositis in North America: case reports and review. Clin Infect Dis. 1992;15(4):668-77. 
14. Turecki MB, Taljanovic MS, Stubbs AY, Graham AR, Holden DA, Hunter TB, Roger LF. Imaging of musculoskeletal soft tissue infections. Skeletal Radiol. 2010;39(10):957-71.

15. Hopkins KL, Li KC, Bergman G. Gadolinium DTPA-enhanced magnetic resonance imaging of musculoskeletal infectious processes. Skeletal Radiol. 1995;24(5):325-30.

16. Nielsen EJ. Tropical pyomyositis in a temperate climate in an immunocompetent adult. Ann Emerg Med. 1992;21(7):880-2.

(c) 2013 Dhanoa et al.; This is an Open Access article distributed under the terms of the Creative Commons Attribution License (http://creativecommons.org/licenses/by/3.0), which permits unrestricted use, distribution, and reproduction in any medium, provided the original work is properly cited.

Peer-review history:

The peer review history for this paper can be accessed here:

http://www.sciencedomain.org/review-history.php?iid=163\&id=12\&aid=835 